\title{
An experimental comparison of Thiol broth with Brewer's thioglycollate for anaerobic blood cultures
}

\author{
D. C. SHANSON ${ }^{1}$ AND M. BARNICOAT \\ From the Department of Clinical Microbiology, University College Hospital, London WC1
}

SYNOPSIS In a series of simulated blood culture experiments, small inocula of eight different strains of Bacteroides and five strains of anaerobic cocci were added to Difco Thiol broth and Southern Group Brewer's thioglycollate. Both methods enabled all of the strains to be isolated after one to three days' incubation, with the exception of Bacteroides melaninogenicus, and most strains to survive after one week. B. melaninogenicus grew more quickly in Difco Thiol broth than in Southern Group Brewer's whereas three strains of anaerobic cocci were isolated first from Southern Group Brewer's. Difco Thiol broth appears to be a satisfactory alternative to Southern Group Brewer's for the isolation of non-sporing anaerobes likely to be found in the blood.

For anaerobic blood cultures, thioglycollate broths have previously been found to give earlier growth of non-sporing anaerobes than cooked meat broths (Forgan-Smith and Darrell, 1974; Shanson, 1974). Southern Group Brewer's thioglycollate appeared to be the only type which allowed reasonable survival of the organisms and was also found to be the best of the media commonly used in Britain (Shanson, 1974). Some American workers use Difco Thiol broth, under vacuum and with carbon dioxide already added, for anaerobic blood cultures (Washington, 1971), and it was decided to compare this medium experimentally with Southern Group Brewer's for the growth of small inocula of nonsporing anaerobes in the presence of fresh human blood. Liquoid was omitted from both types of medium since some strains of anaerobic cocci are inhibited (Hoare, 1939) especially when it is added to thioglycollate (Shanson, 1974).

\section{Materials and Methods}

\section{BACTER I A}

Bacteroides fragilis NCTC 9343, Sphaerophorus necrophorus NCTC 10575, Bacteroides necrophorus NCTC 7155, Bacteroides melaninogenicus NCTC 9337, anaerobic coccus NCTC 9801, and anaerobic coccus NCTC 9803 were obtained from the National

${ }^{1}$ Present address: Department of Medical Microbiology, The London Hospital Medical College, London E1.

Received for publication 21 November 1974.
Collection of Type Cultures. The other strains were freshly isolated from routine wound swabs on blood agar and included two strains of $B$. fragilis, two strains of $B$. melaninogenicus, and three strains of anaerobic cocci.

\section{MEDIA}

Southern Group Brewer's thioglycollate (0586 C), $80 \mathrm{ml}$, without liquoid.

Difco Thiol broth (0355-37-8), $50 \mathrm{ml}$, under vacuum and with carbon dioxide, without liquoid, prepared by the manufacturers.

Cooked meat medium (0530) in bottle with perforated cap from Southern Group Laboratories.

BLOOD

Fresh human blood was obtained from healthy volunteers. After collection the blood was introduced directly into the blood culture bottles; $5 \mathrm{ml}$ was obtained from each donor not more than 30 minutes before each test.

INOCULATION

The inoculum was calculated by making viable counts of 72-hour cooked meat cultures of the strains to be tested by the Miles and Misra method. Laked blood was added to the cooked meat broth in order to obtain better growth of B. melaninogenicus but was not required for the other species. After preliminary tests $0.5 \mathrm{ml}$ of the dilution likely to contain the required number of viable organisms 


\begin{tabular}{|c|c|c|c|c|c|c|c|c|c|}
\hline \multirow[t]{2}{*}{ Organism } & \multirow[t]{2}{*}{ Inoculum ${ }^{1}$} & \multicolumn{4}{|c|}{ Difco Thiol } & \multicolumn{4}{|c|}{ Southern Group Brewer's } \\
\hline & & $24 h r$ & $72 \mathrm{hr}$ & $96 \mathrm{hr}$ & I week & $24 h r$ & $72 \mathrm{hr}$ & $95 \mathrm{hr}$ & I week \\
\hline \multicolumn{10}{|l|}{ B. fragilis } \\
\hline NCTC 9343 & 27 & + & + & + & + & + & + & + & + \\
\hline Lab 1802 & 40 & + & + & + & + & + & + & + & + \\
\hline Lab 1902 & 7 & + & + & + & + & + & + & + & + \\
\hline \multicolumn{10}{|l|}{ B. necrophorus } \\
\hline NCTC 1755 & 46 & 0 & + & + & + & + & + & + & + \\
\hline \multicolumn{10}{|l|}{ S. necrophorus } \\
\hline NCTC 10575 & 3 & 0 & + & + & - & + & + & + & + \\
\hline \multicolumn{10}{|c|}{ B. melaninogenicus } \\
\hline NCTC 9337 & 20 & 0 & + & + & + & - & 0 & + & $\rightarrow$ \\
\hline \multirow{2}{*}{$\begin{array}{ll}\text { Lab } 0558 & 1 \\
& 2\end{array}$} & 41 & \pm & + & + & $\cdots$ & 0 & $\mathbf{0}$ & $\div$ & + \\
\hline & 25 & 0 & + & + & + & 0 & 0 & 0 & + \\
\hline Lab 5656 & 27 & 0 & + & + & + & 0 & 0 & \pm & + \\
\hline \multicolumn{10}{|l|}{ Anaerobic cocci } \\
\hline NCTC 9801 & 58 & 0 & + & + & - & + & + & + & + \\
\hline NCTC 9803 & 29 & + & + & + & + & + & + & + & + \\
\hline Lab 4450 & 34 & + & + & + & $i$ & + & + & 1 & 0 \\
\hline Lab 1855 & 82 & 0 & + & + & 0 & + & + & + & 0 \\
\hline Lab 2690 & 44 & 0 & + & + & + & $\perp$ & + & $\perp$ & + \\
\hline
\end{tabular}

Table Results of subculture of the blood broths

${ }^{1}$ Viable particles per bottle:

+ growth in all three bottles

\pm growth in two of three bottles

0 no growth, or growth in only one of three bottles

was inoculated into the test blood-broths by puncturing each cap with a separate needle attached to a disposable $1 \mathrm{ml}$ syringe. The actual inoculum was checked on each occasion by concurrent viable counts of the dilution inoculated using blood agar incubated in anaerobic jars containing $10 \%$ carbon dioxide. Colonies were counted after 48 hours' incubation.

\section{METHOD FOR EACH EXPERIMENT}

Blood from each donor was distributed so that possible differences between their blood would not affect the comparison between the methods, and $5 \mathrm{ml}$ blood was added to each bottle. Each medium was tested in triplicate. After inoculation the bottles were incubated without the use of an anaerobic jar, at $35^{\circ} \mathrm{C}$, with their caps screwed on tightly. In some tests further sets of Southern Group Brewer's were also incubated with their tops vented by a needle containing a sterile cotton wool plug or with their caps loose, or with the tops vented by a plugged needle in air plus $10 \%$ carbon dioxide to discover whether the addition of carbon dioxide was beneficial even though exposure to air would also be increased.

Bottles were subcultured onto blood agar after one, three, four, and seven days' incubation. The blood agar plates were incubated in anaerobic jars containing $10 \%$ carbon dioxide for up to four days, anaerobiosis being checked with an external indicator.

\section{Results}

These are summarized in the Table. No difference was found between the two methods for the earls growth and survival of $B$. fragilis. Three strains of $B$. melaninogenicus were all more rapidly isolated from Difco Thiol broth. Southern Group Brewer's. appeared to facilitate the better isolation of anaerobis cocci, after 24 hours' incubation.

When vented, in either air or carbon dioxide growth as judged by the blood agar subculture plate was reduced to about one-third that found or subculture plates from parallel Brewer's which had been incubated with the caps tight, on the firse positive subculture. This phenomenon was observed with two strains of $B$. fragilis, one strain of $B$ melaninogenicus, and two strains of anaerobic cocciv

\section{Discussion}

Many anaerobes do not survive in USP thioglycollate (Shanson, 1974). This effect was also noted b\& Forgan-Smith and Darrell (1974), who suggeste that a good cooked meat method be used together with USP thioglycollate for each routine bloog culture. However, it is probable that some anaerobes which do not survive after one week in USP thio ? glycollate will not grow in the cooked meat, since thioglycollate methods were found to be superio to cooked meat methods for the isolation of anaerobes? 
On experimental grounds a reliable system which requires only one anaerobic bottle in each routine blood culture set is provided for by using Southern Group Brewer's thioglycollate (Shanson, 1974). From the results presented in this paper it would appear that Difco Thiol broth represents a suitable alternative to Southern Group Brewer's for use as a routine anaerobic blood culture bottle. In any case where an anaerobic bacteraemia is strongly suspected it might prove beneficial to inoculate blood into both Southern Group Brewer's and Difco Thiol broth, since there are certain anaerobes which can most speedily be isolated by one method rather than the other. As might be expected, Southern Group Brewer's appears to give the best results when the caps are tight and not vented, the introduction of air with the carbon dioxide in these bottles being undesirable. The effect of adding carbon dioxide to anaerobic liquid media other than Thiol broth, without venting or loosening the caps, has yet to be determined.

We should like to thank Dr Joan Stokes for helpful advice in the preparation of this paper.

\section{References}

Forgan-Smith, W. R. and Darrell, J. H. (1974). A comparison of media used in vitro to isolate non-sporing Gram-negative anaerobes from blood. J. clin. Path., 27, 280-283.

Hoare, E. D. (1939). Suitability of 'liquoid' for use in blood culture media, with particular reference to anaerobic streptococci. J. Path. Bact., 48, 573-577.

Shanson, D. C. (1974). An experimental assessment of different anaerobic blood culture methods. J. clin. Path., 27, 273-279.

Washington, J. A., II (1971). Comparison of two commercially available media for detection of bacteremia. Appl. Microbiol., 22, 604-607. 
matters but the bulk of the volume is devoted to correlations between clinical aspects and histology.

The section by Sherman dealing with differentiation during embryogenesis evokes some important and fundamental issues which sit somewhat uneasily in this largely practical manual. Franzen summarizes his considerable experience with aspiration biopsy, a technique which is perhaps worthy of more widespread adoption. There is an interesting presentation by Casarett and his colleagues describing a quantitative histological approach to radiosensitivity and response which does attempt to get to grips with the problem of providing an objective histological measure of therapeutic response.

In the clinical section there are two chapters on the prognostic significance of histological grade in breast cancer. The first by Hutter discusses the general aspects of pathology in relation to prognosis, and the second by Bloom describes in some detail his well-known earlier studies on tumour grading in breast tumours in relation to patient survival. The clinical section, which also deals with histology in relation to lung, bladder, and prostatic cancer, describes the current position in Hodgkin's disease where it is of considerable interest that the prognostic significance of the histological sub-type appears to be changing so that the distinction between nodular sclerosis and mixed cellularity may be less important than was previously thought. This emphasizes an important consideration in the identification of prognostically significant features in any human malignancy, namely, that with changing investigative and therapeutic attitudes features which once significantly determined prognosis may no longer do so.

With the reservations expressed above, this latest edition of the excellent series of Frontiers of Radiation Therapy and Oncology maintains the high standard set by the previous volumes and will be of interest and value to both pathologists and clinicians working in the cancer field.

M. J. PECKHAM

Laboratory Instrumentation. Edited by R. Hicks, J. R. Schenken, and Mary Ann Steinrauf. (Pp. 237; 135 figs; \$9.95.) London, Maryland, New York, San Francisco: Harper and Row. 1974.

The authors' intention is to attempt to bridge the gap between the larger textbooks on theory and the manufacturers' instrument manuals. It was developed for use as an instructional course manual by the faculty of medical technology of a United States university.

The book is divided into 18 sections; the first deals with the elementary principles of electricity in 20 pages. Other subjects covered are spectrophotometry, pH + blood gas analysis, osmometry, refractometry, scintillation counting, gas-liquid chromatography, the Coulter A, B, Fn + S, the Technicon Autoanalyzer, balances, diluters, and centrifuges.

Each section starts with a glossary of definitions which is followed by an explanation of instrument components and how they are incorporated in a typical instrument. Each chapter includes its own set of refrences.

No attempt is made to compare different makes of instrument. The preface states that mention of a specific instrument is not an endorsement of the instrument nor is failure to mention a particular instrument an indication of inferiority or unacceptability.

The authors have of necessity had to be selective but there are some important omissions. No mention is made of rate reaction analysers, discrete analysers such as the Vickers multi and dual channel machines or specific glucose analysers, and only four pages are devoted to fluorimetry, whereas refractometry is allocated 14 pages. A glossary of abbreviations is provided at the beginning of the book, which is useful except that the abbreviation for aspartate amino transference is given as S.G.O.T!

A section giving some guidance on how to check the validity of makers' claims of performance would be useful.

Despite these criticisms, the book is well produced, easy to use, and well illustrated with simple line drawings.

I think this book should be of value to those studying for $\mathrm{HNC}$ and the Advanced Final of the IMLT, the MCB, MRC Path in clinical chemistry, and wherever a basic knowledge of the principles of operation of instruments used in the medical laboratory is required.

JOYCE L. BELL

\section{Errata}

In Antibiotic-disc tests for rapid identification of non-sporing anaerobes by Susan Peach (J. clin. Path., 1975, 28, 388-391) the results shown in table II regarding the susceptibility of $B$. fragilis to rifampicin have been printed the wrong way round. Instead of:

Rifampicin $15 \mu \mathrm{g}$

$$
\text { R } 100
$$

the table should read:

Rifampicin $15 \mu \mathrm{g}$

$\begin{array}{ll}\mathrm{R}- & 2 \cdot 5 \\ \mathrm{~S} 100 & 97 \cdot 5 \\ \text { Intermediate } & -\end{array}$

In An experimental comparison of Thiol broth with Brewer's thioglycollate for anaerobic blood cultures by D. C. Shanson and M. Barnicoat (J. clin. Path., 1975, 28, 407-409) there was an error in the table. B. melaninogenicus strain NCTC 9337 should have appeared with a 0 in the $24 \mathrm{hr}$ column, with Southern Group Brewer's medium, instead of the + shown. 